\title{
The Roles of Saudis Human Resources Management as Strategic Business Partner: Toward Accomplishing the Saudis 2030 Vision
}

\author{
ABDULRAHMAN, ALI ALHAZEMI \\ Associate professor, College of Business, Jazan University, Saudi Arabia. \\ Email: afalhazmi@jazanu.edu.sa
}

\begin{abstract}
The general objective of this article was to identify factors that influence effective strategic planning process in Saudi Arabia organizations. It examined carefully the critical factors that influence strategic planning in Saudi Arabia and why organizations must plan for the future to remain relevant in the new Saudi business environment. This will be accomplished by aligning the organization strategic plan with the 2030 Saudi vision and mission. The article explores the connection between Saudi strategic plans with organization structure, organizational culture, leadership and human resources in Saudi Arabia. This paper specifically analyses the factors that influence strategic planning in Saudi Arabia and recommendations that can be employed in order to have a fruitful implementation of strategic planning in the organizations in Saudi Arabia. The recommendations will also address the gaps that have been identified in this paper.
\end{abstract}

Keywords: 2030 Saudi Vision, Saudi Strategic Planning, Saudis Organization Structure, Saudis Organizational Culture, Saudis Human Resource.

\section{Introduction}

Many studies suggested that strategic tools used in the business sectors had illustrated their usefulness in the strategic domain (Sharma, 1999; Hussey, 2002; Orndoff, 2002; Frost, 2003; Poister, 2005). For Saudis business, effective strategic management in public sectors requires the application of private sector's tools in public sector's activities which is often measured against target outcomes (Fu-Lai Yu, 2003; Al Hijji, 2014). The current review presents two strategic management analytical frameworks which could be helpful to Saudis public sector's strategists as achieve greater added value in service provision and stakeholders' expectations (Cong \& Pandya, 2003).

This review starts in the context of new public management (NPM) and the application of strategic management frameworks that may be used to meet the NPM challenges. In addition, it shows the importance of using stakeholder and value chain analyses to strategists in Saudis public sector's managers by highlighting the importance of using such strategic frameworks, without careful consideration of standard conditions, selection and contextual adaptation in public sector. Accordingly, this study emphasizes the need for Saudis business leaders today to adapt their practices to the use of such frameworks.

Nowadays, Saudis human resources management are the most important factor of accomplishing the 2030 Saudis vision set by its leaders. Human resources are the most important assets of an organization as it focuses on strategic planning, which focuses to cover special educational skill needs in the Saudis field. 
The Best utilization of Saudis human resources in today situation can lead to a competitive advantage which can be achieved through management improvement of administrative people. In other words, Saudis human resources improvement not only achieves through providing specialized or technical training to employees but also the applying of the strategic management in the realm of management and providing development opportunities toward accomplishing the Saudis 2030 vision.

Today, Saudis human resources are the strategic resources for an organization is considered an integral part of strategic management, which means that Saudis business planning and human resources are strategically connected in nature.

It's clear that Saudis 2030 vision is the most important factor that can lead to a new approach in the strategic planning of human resource, where the process of technological, social, and economic changes occurred both inside and outside of the kingdom of Saudi Arabia.

Saudi Arabia should consider many various requirements in order to keep in line with any ongoing changes. Today, the most important factor of Saudis business is a human resource. Therefore, the cooperation and coordination of Saudis human resource managers and business management leaders are important foundations for the construction of human resources strategies that are composed of two parts, Saudis strategic management framework and value-based evaluation.

\section{The Literature Review}

\section{Saudis Strategic Management Framework}

This article provides a roadmap of the Saudis strategic planning process for business in general as well as the Saudis HR function.in order to accomplish the 2030 vision for Saudi Arabia, which include:

- Assessing an organization's current situation alien with a 2030 vision.

- Envisioning and articulating an organization's desired future related to the 2030 vision.

- Formulating a strategy and identifying the strategic objectives to achieve the 2030 vision.

- Implementing the strategy related to the 2030 vision.

- Monitoring the strategy to assure it is successfully implemented.

There have been many discussions on the use of traditional strategic frameworks in the Saudis public sector. The strategic frameworks and moreover prescriptive models that are used might not succeed. This failure stems from poor strategic planning frameworks which need revisions to fit the existing 2030 Saudi strategic situation in the public sector.

Wilkinson and Young (1994) emphasized the importance of the interaction processes clarity between a business organization and its stakeholder groups, to manage suggested received value to the stakeholders (Radnor \& McGuire, 2004; Gannon, Roper, \& Doherty, 2015).

One of the strategic values in the business domain is a value chain model which is derived from the company's accounting tools (Lengnick-Hall, Lengnick-Hall, \& Rigsbee, 2013). Porter (1985) introduced and added the concept of the value chain into the set of strategist's analytical tools, as it emphasizes in internal and external linkages of the organizations' value creation (Williamson, 1975).

The general model of the value chain illustrates the interconnection between many activities, included but not limited to internal logistics, operations, external logistics, marketing, sales and services - economic foundation, human resource management, technology development, and procurement. These activities are important for an organization to function appropriately, but more importantly, they can make value especially in service-based industries or everywhere that servicing is a key component. Many studies 
focused on the advantages of collaboration within a value network activities to emphasis on the transaction costs of implementing network's performance (Barley, Freeman \& Hybels, 1992; Brooks \& Reast, 1996; Collins \& Belcher, 1999; Harland, Lamming \& Cousins, 1999; Pearce, Robinson \& Subramanian, 2000; Hinterhuber, 2002;). It is likely that Saudis public sector organizations enhance real and perceived efficiency and effectiveness in service delivery and understanding the linkages between value activities within the value network.

The stakeholder groups complexity in the public sector organizations is probably more complexities than in private sector organizations. Therefore, applying a value network approach management emphasis can move operations towards developing communication processes and co-operation in the whole network (Walters \& Jones, 2001). Using a value network perspective will help Saudis public sector strategists to focus on investor and knowledge' values. Thus, allows the total system of value creation to be examined (Payne \& Holt, 2001).

This analysis provides a comprehensive approach towards business activities (manufacturers, retailers, wholesalers, and suppliers) in Saudi Arabia to accomplish the vision of 2030.

\section{Saudis Investor Mapping Model}

One of the most strategic important tools that have been developed to help in evaluating and managing a network of stakeholders is stakeholder mapping (Bryson, 2003). Stakeholders or investors defined as an individuals or groups that can influence firmly the creation of organizational values (Freeman \& Liedtka, 1997; Schneider, 2002; Freeman, 2010; Jackson, Schuler \& Jiang, 2014).

Stakeholders can be classified in terms of their level of interest or/and their level of power. Both classifications are intellectual and substantial for understanding the business priorities and stakeholders' expectations (Johnson, Scholes \& Whittington, 2005). The changing position of stakeholders made this model a dynamic model, as it provides a good understanding of stakeholders' desired position to understand the strategic Saudis situation in both the public and private sectors. both Saudis public and private sector organizations have a strong relation to their stakeholders. Value chain analysis may require adaptation especially when it is used in the context of Saudis public sector. However, there is a need for significant adaptation of this model for meaningful and effective strategic application in the public-sector activities (Williams \& Lewis, 2008).

\section{Maintenance of Saudis Human Resource}

It is very important for Saudi Human Resources (HR) to develop effectiveness and efficiencies on all aspects of the employees, Saudi HR is the cornerstone of an organization if it is managed by skilled and well-trained HR employee to help the organization succeed and grow in the business. Therefore, Saudi HR management need to understand the entire business aspects to carry out strategy and approaches to accomplish the organization goal consequently achieve the country of 2030 vision. One of the most challenging tasks of the senior Saudi Arabia HR management is the retention of intelligent, skilled and capable human resources. This could be achieved by two aspects including the financial incentive programs which are designed to inspire employees' loyalty, increase productivity and profitability among employees such as the competitive advantage of salaries, bonuses, and other financial benefits. Another aspect is the non-financial incentive programs such as job security, occupational prestige, having a sense of personal worth and importance, and clarifying the occupational future.

Many Saudi HR management experts believe that attention and resources should be directed toward continuous training and ongoing development for all staff members in the organization which will lead to the development of long-term and permanent competitive advantages that contributed to the 2030 vision. 


\section{Saudi Assessment and Performance Management}

Assessment and performance management considered the most important in developing of Saudi human resources because it leads to organizational performance enhancement. The revising and continuous evaluation of Saudi employees' work performance highlights employees' strengths, weaknesses and provides a summary of organizations' and administrators' goals in several time frames. Performance management actions provides an opportunity for interaction, participation, setting organizational management objectives which may result in improving organizational performance (Saadat, 1996).

\section{Promotion of Saudi Organizational Culture}

In the ground of Saudi culture, many factors such as encouraging employees to continuously improve and increase their technical level, effectiveness and efficiency are essential with long-term cultural activities via using the knowledge management and learning organization's course orientation. However, these factors do not always suitable to some Saudis human resources which can have a negative impact in the short term. Recently, successful Saudi companies in business areas find out that they cannot be successful without effectively applying principles of strategic human resource management and linking strategic practices with the overall organizational strategic performance. The main elements in the implementation of this process are to obtain full support from senior human resource management at all levels (Zarei, 1992).

\section{Strategic Planning and Human Resources}

Planning is the process of identifying organizational goals and achieve them strategically to complete effectively the organizational vision and goal. Strategic planning is a systematic process for making fundamental decisions and establishing plans to set organizational activities within a legal framework. Strategic planning is different from tactical planning, So, it's a process focused on sequences of actions to obtain short-term goals within a year or less. In addition, Saudi strategic and tactical plans are developed separately, in fact they are inseparable in achieving business success. Saudi strategic planning typically affects every aspect of organizational operations, while tactical planning is not. Furthermore, the advantages of strategic planning are extensive, even though some may be indirect. Therefore, the full benefits of strategic planning may be difficult to quantify in terms of a strict return-on-investment (ROI) basis. Nevertheless, it is easy to generalize the expected benefits to other departments. The scheduling of the strategic planning process depends on the organizational nature, needs, and the immediate external environment, it might be carried out once or twice a year based on some specific criteria, which include but not limited to mission, vision, values, environmental scan, goals, strategies, responsibilities, timelines, budgets, etc. The Saudi human resource planning is a process for assessing the demand and evaluating the size and the nature of supplies that are required to meet the Saudi business needs. Thus, every staff member in human resources management should fully understand the organizational needs. Then link it with the strategic planning in accordance to country policies related to achieve 2030 Saudi vision. Figure 1 shows that there is a close relationship between Saudi human resource planning and strategic planning.

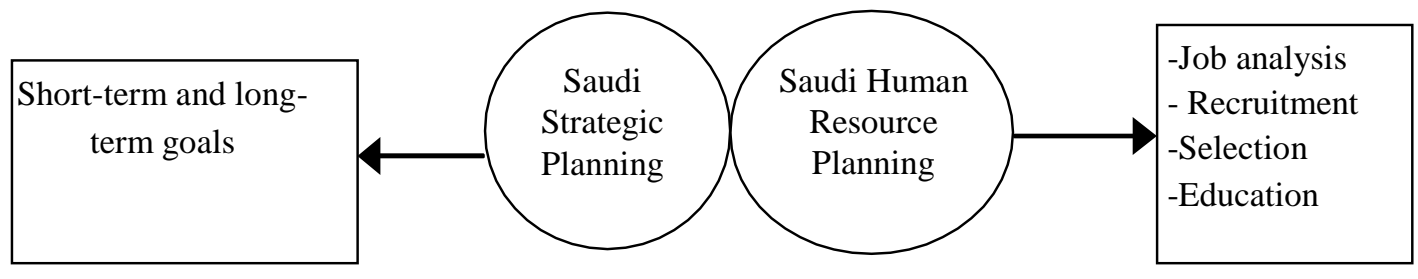

Figure 1. The Link between Saudi Strategic Planning and Human Resource Planning 


\section{Saudi Strategic Human Resource Planning toward 2030 Vision}

Decenzo and Robbins (2005) defined human resource planning as an organizational process to determine the right number of expertise and skilful employees to achieve overall goals. In Saudi Arabia, Saudi human resource planning is used to analyze and evaluate the balance between supply and demand by using a structured framework which might provide a clear image of the plan of an organization. Therefore, it focuses on achieving the tasks by skilful peoples every day. In addition, there is a need to consider the workers effectiveness of a company toward accomplishing 2030 Saudi vision. Therefore, all Saudi organizations need a comprehensive understanding of their employees, characteristics, and relationships within the organization. Furthermore, Saudi human resource planning must be linked to the various external factors such as Saudi economic pressures, Saudi technological changes and advancements, new Saudi rules and regulations, political situations, education, labour market and the internal factors such as organizational objectives, culture, structure, leadership behaviour, human resources policies, and stakeholders. Accordingly, Saudi organizations should be connected to human resource planning in three ways: Basic planning, process planning, and organizational planning. The basic planning focuses on qualified employee resources, while the planning process focuses on the intradepartmental and interdepartmental process. Finally, organizational planning is a type of planning which includes organizational issues, resources, and objectives for an organization, such as decisions related to the numbers of the employees, patterns of working hours, and different contract forms to accomplish the 2030 Saudi vision. Some of the Saudi organizations are interested in increasing their employees' abilities and capabilities through periodically transferring employees from one task to other, while others show a tendency towards training grounds for scarce skills of their employees for a long period of time. The Saudi human resource planning should require all organizations to identify challenges that face the business during decision- making. Furthermore, this thought foundation cannot achieve without critical thinking.

\section{Barriers for Saudi Human Resources (HR) Planning}

Barriers in the implementation of human resource planning in Saudi organization must be identified to deal with it, in order to achieve the 2030 vision on time. Most common barriers of Saudi human resources planning that were highlighted by experts are doubt about planning and predicting in special cases, interference resistance of operating units against central units, lack of connection between various activities in planning process especially business, financial, and personnel planning, conflicts in human resources made by financial and personnel units, lack of relationship between budgeting and strategic planning, inappropriate techniques for assessing Saudi future needs, lack of adequate attention to qualitative aspects, and distrust and suspicion toward planning units.

\section{Saudi Human Resource Strategic Design}

The Saudi strategic human resource planning is a process designed to integrate all Saudis human resource planning and strategic planning toward the 2030 Saudi vision. This pattern reflects the organizational autonomy at different levels of organizational structure in order to contribute and improve the overall organizational performance, taking an active role in the development of Saudi human resources which supports the continuous improvement of the Saudi organization, making a clear communication between the main activities of the business and human resources, designing planning tools that provide required supports and facilities for human resource development and performance toward the 2030 vision.

\section{Saudi Human Resource Strategic Process}

The Saudi Strategic process consists of explaining and defining strategic positions, objectives, strategic decisions, analyzing the internal and external environment, such as analysis of strengths, weaknesses, opportunities, and threats (SWOT), programs in order to achieve the 2030 Saudi vision. 


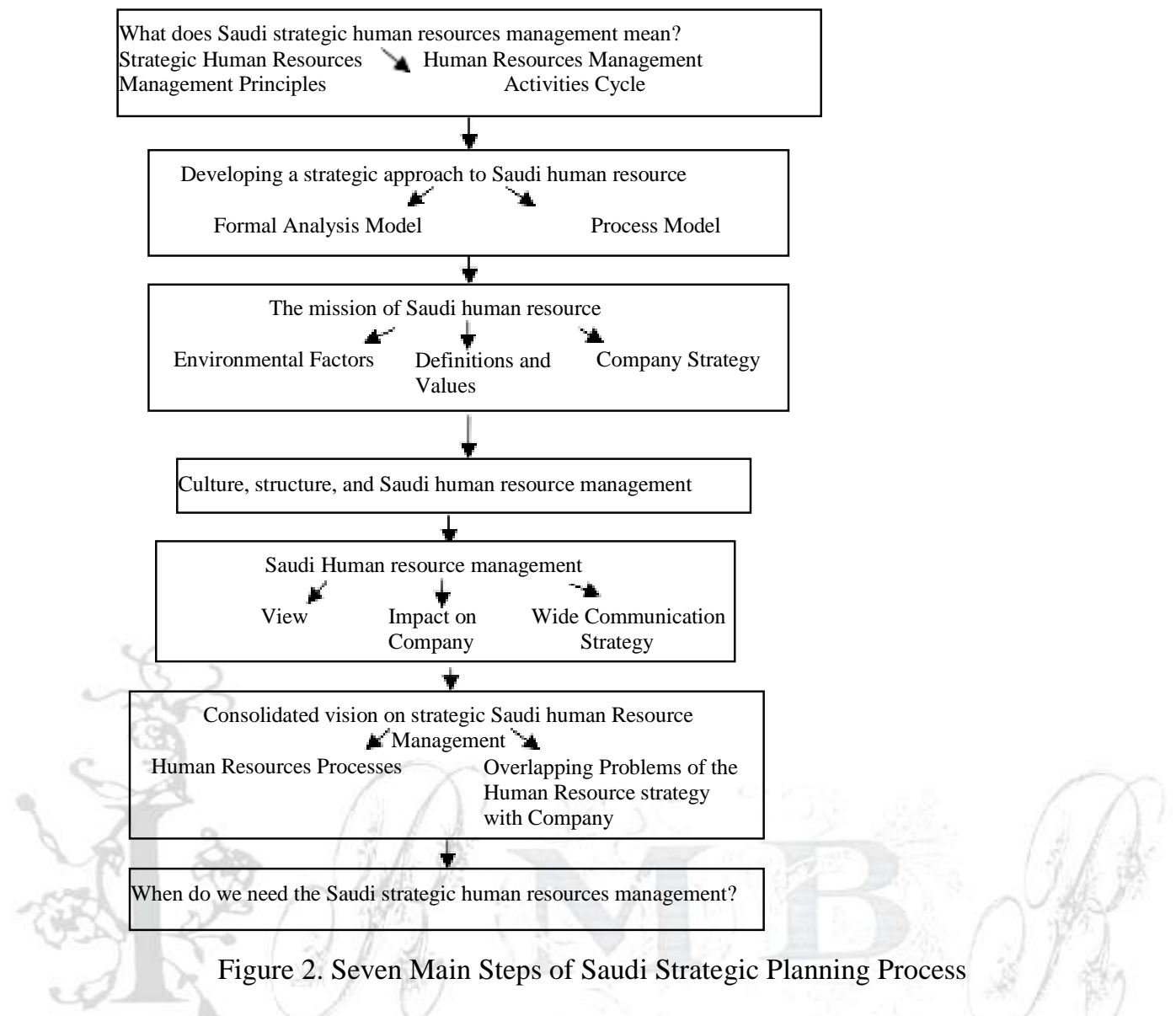

Models of Human Resource (HR) Strategic decisions are strategic purposes of the organization aspects act collectively to achieve it vision in aligned with a achieving Saudi 2030 vision. Analysis of internal environment consisted of microanalysis of Saudi intra-organizational challenges, employees skills, organizational structure, supply ability, stock, sales, defining the human resource status, and designing programs to achieve organizational objectives associated with the 2030 vision. Analysis of external environment refers to identification and analysis of Saudi organization's external key factors that have a potential effect on human resource management of an organization, such as economics technology changes, capital market, educational and cultural situation, demographic, political factors, economic, social, cultural factors, technology development, and labor supply. Analysis of SWOTs assumes an effective strategy which increases the strengths, increases opportunities and at the same time decreases its weaknesses and threats toward achieving the 2030 Saudi vision. For example, understanding Saudi changing market, understanding industry competition, and technological changes are considered as opportunities for all businesses and institutions. Saudi businesses growth, rules, and regulations are considered as threats which have main effects on the institutional environment. Weaknesses are lack of, or limitation of resources, skills, and abilities which impede the efficacy of planning, while factors such as equipment's, financial resources, management skills, and marketing can be sources of strength. In addition to programs which consisted of strategies, policies, and development frameworks of human resources that obtain through training, job rotation, and promotion. Therefore, Saudi human resource planning process refers to micro and macro analysis of human resource variables, organizational culture, physical atmosphere, organizational structure, quality of working life, job skills, fitness level, benchmarking, assessment of human resource outcomes, human resource development and measurement tools, and corrective actions. 


\section{Saudi Human Resources management and James -Walker Model and analysis}

\section{James -Walker Model}

James -Walker Model process consisted of three segments including strategy of the institute, strategic path, and implementing human resource management which has a mutual effect on each other (Walker, 1992).

Table 1. James Walker model

\begin{tabular}{l}
-Strategy of the institute $\begin{array}{l}\text { Internal and external environmental issues related to institute changes } \\
\text { - Strategic path } \longrightarrow \text { Issues related to human resources and human resources strategy }\end{array}$ \\
\hline
\end{tabular}

\section{Formulate a Strategy and Strategic Objectives to Accomplish the Saudi 2030 Vision}

Once an organization has laid the groundwork, the next step is for the Saudi leader strategic planning team is to develop a strategic plan to fulfil the objectives in both long and short term. The focus in this phase is to determine how the organization can attain its desired future embodied by its vision, mission and values statements toward the Saudi 2030 vision.

The strategy is defined as an organization's plan for controlling and using its resources in furtherance of its interests. A strategy should broadly specify how the Saudi organization will create and sustain advantages over its competitors. Some common strategies for achieving a competitive advantage include:

- Increasing cost-effectiveness.

- Distinguishing the organization through product innovation or service differentiation.

- Highlighting service and customer satisfaction.

- Striving to become the dominant player in the market.

After formulating a strategy of the organization, it is the time to set up strategic objectives. Strategic objectives are the main milestones of an organization to achieve its ultimate destination. Strategic objectives composed of long-term objectives to be achieved within three to five years. such of these longterm objectives are sales, market segments, finances, operations, technologies, employment or profits.

\section{Implement Saudi Strategic Objectives and Strategy}

Strategic planning considered as a comprehensive process because it evaluates each part in the organizational functions, it is viewed as a leadership responsibility in its first stages. Once organizational leaders have established the strategy and strategic objectives, it is the time for the leaders to step back and allow managers to implement the objectives and strategy inappropriate way. The strategic planning team and the organization's leaders together continue their role of providing high-level guidance, but they allow managers to perform their roles in translating leadership initiatives into day-to-day implementation.

\section{Establish a Mechanism to Evaluate Progress for Saudi Human Resource (HR)}

Saudi organizations should ask on an ongoing basis, "How will we know if we are on the right track toward the intended destination?" Accordingly, the last step in the strategic planning involves monitoring and evaluating progress toward the achievement of strategic objectives. Most Saudi organizations conduct an annual or quarterly strategic review for this purpose. This review should:

- Assess if the organization is on the track toward achieving key objectives. If not, appropriate corrective actions should be considered. 
- Provide the opportunity to identify and adapt to significant internal or external changes that could affect the strategic plan.

- Update annual action priorities.

In addition, all Saudi organizations can use tools such as balanced scorecards, benchmarking and dashboards to keep them focused on the strategy and key success indicators.

\section{Conclusions}

Human resource is the most valuable factor of production and the main source of competitive advantage in Saudi business. Saudi labour factor is considered as a strategic resource for organizations. Therefore, human resource planning is a part of strategic planning. Saudi Human resource planning recognized the following criteria in achieving 2030 Saudi vision, which includes but not limited to decision- makings, proper prediction, good judgment, recognizing the present external and internal conditions or SWOT analysis that affecting the organization's activities.

Strategic analysis in Saudi HR requires a comprehensive understanding of the communications network around issues. The value chain and stakeholder mapping analyses have been used historically to enable researchers to understand the present association. Value chain and stakeholder mapping analyses help to reach a better understanding of the fitness between an individual's value system and a perceived organizational value system. They can lead to a greater sense of ownership, and governmental performance in local communities.

Although every organization's strategic plan is unique, the demographics and other characteristics of the available workforce have a major effect on the way businesses are staffed, and the way organizations are staffed has a significant impact on the execution of the organization's strategy. Consequently, HR professionals should monitor, and respond accordingly, to factors that may affect workforce composition.

\section{References}

Al Hijji, K. Z. (2014). Strategic management model for academic libraries. Procedia-social and Behavioral sciences, 147, 9-15.

Barley, S. R., Freeman, J., \& Hybels, R. C. (1992). Strategic alliances in commercial biotechnology. Networks and organizations, 311-347.

Brooks, I., \& Reast, J. (1996). Re-designing the value chain at scania trucks. Long Range Planning, 29(4), 514-525.

Bryson, J. M. (2003). Strategic planning management. In B. G. Peters \& J. Pierre (Eds.), Handbook off public management (pp.38-47). Thousand Oaks, CA: SAGE.

Collins, R., \& Bechler, K. (1999). Outsourcing in the chemical and automotive industries: choice or competitive imperative? Journal of Supply Chain Management, 35(3), 4-11.

Cong, X., \& Pandya. K. (2003). Issues of knowledge management in the public sector. Journal of Management Studies, 39(1), 25-32.

Decenzo, D. A., \& Robbins, S. P. (1999). Human Resource Management: concepts and applications. New York: John Wiley \& Sons.

Freeman, E., \& Liedtka, J. (1997). Stakeholder capitalism and the value chain. European Management Journal, 15(3), 286-296.

Freeman, R. E. (2010). Strategic management: A stakeholder approach. Cambridge university press.

Frost, F. A. (2003). The use of strategic tools by small and medium-sized enterprises: an Australasian study. Strategic Change, 12(1), 49-62.

Fu-Lai Yu, T. (2003). A subjectivist approach to strategic management. Managerial and Decision Economics, 24(4), 335-345.

Gannon, J. M., Roper, A., \& Doherty, L. (2015). Strategic human resource management: Insights from the 
international hotel industry. International Journal of Hospitality Management, 47, 65-75.

Harland, C. M., Lamming, R. C., \& Cousins, P. D. (1999). Developing the concept of supply strategy. International Journal of Operations \& Production Management, 19(7), 650-674.

Hinterhuber, A. (2002). Value chain orchestration in action and the case of the global agrochemical industry. Long range planning, 35(6), 615-635.

Hussey, D. (2002). Company analysis: determining strategic capability. Strategic Change, 11(1), 43-52.

Jackson, S. E., Schuler, R. S., \& Jiang, K. (2014). An aspirational framework for strategic human resource management. The Academy of Management Annals, 8(1), 1-56.

Johnson, G., Scholes, K., \& Whittington, R. (2005). Exploring corporate strategy. Harlow, NJ: FT.

Lengnick-Hall, M. L., Lengnick-Hall, C.A., \& Rigsbee, C. M. (2013). Strategic human resource management and supply chain orientation. Human Resource Management Review, 23,366-377

Orndoff, K. (2002). Strategic tools for RIM professionals. Information Management, 36(6), 65.

Payne, A., \& Holt, S. (2001). Diagnosing customer value: Integrating the value process and Relationship Marketing. British Journal of Management, 12(2), 159-82.

Pearce, J. A., Robinson, R. B., \& Subramanian, R. (2000). Strategic management: Formulation, implementation, and control. Columbus, $\mathrm{OH}$ : Irwin/McGraw-Hill.

Poister, T. H. (2005). Strategic planning and management in state departments of transportation. International Journal of Public Administration, 28, 1035-1056.

Radnor, Z., \& McGuire, M. (2004). Performance management in the public sector: Fact or fiction? International Journal of Productivity \& Performance Management, 53(3), 245- 260.

Saadat, E. (1996). Human resource management. Tehran: SAMT publication.

Saha, N., Chatterjee, B., Gregar, A., \& Sáha, P. (2016). The impact of SHRM on sustainable organizational learning and performance development, International Journal of Organizational Leadership, 5 (1), 6375.

Schneider, M. (2002). A stakeholder model of organizational leadership. Organization Science, 13(2), 209220.

Sharma, S. (1999). Trespass or symbiosis? Dissolving the boundaries between strategic marketing and strategic management. Journal of Strategic Marketing, 7, 73-88.

Walker, A. J. (1992). Handbook of human resource information systems: Reshaping the human resource function with technology. McGraw-Hill, Inc.

Walters, D., \& Jones, P. (2001). Value and value chains in healthcare: a quality management perspective. The TQM Magazine, 13(5), 319-335.

Wilkinson, I.F., \& Young, L. C. (1994). Business dancing: The nature and role of inter-firm relationships in business strategy. Australasian Marketing Journal, 2(1), 67-79.

Williamson, O. (1975). Market and hierarchies: Analysis and antitrust implications. New York: The Free Press.

Zarei, M. H. (1992). Strategic planning to strategic resources: Knowledge management. Tehran: Tehran University Press. 